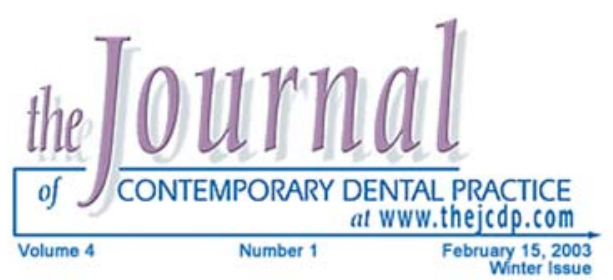

\title{
A Review of Drug-Induced Oral Reactions
}

\section{Mohammad Abdollahi, PharmD, PhD; \\ Mania Radfar, PharmD}

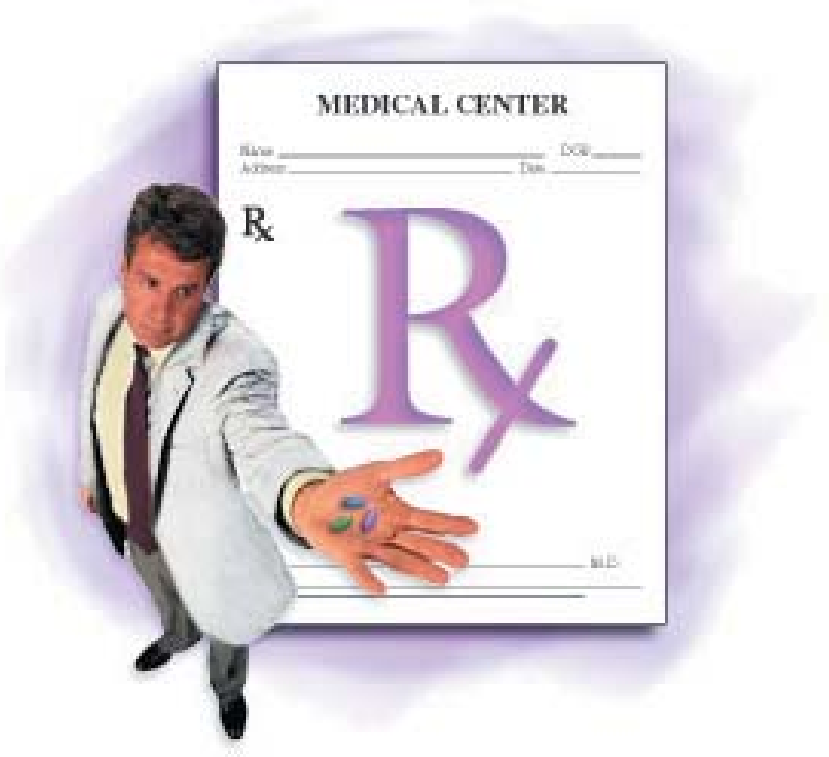

Abstract

Every drug can produce untoward consequences, even when used according to standard or recommended methods of administration. Adverse drug reactions can involve every organ and system of the body and are frequently mistaken for signs of underlying disease. Similarly, the mouth and associated structures can be affected by many drugs or chemicals. Good oral health, including salivary function, is very important in maintaining whole body health. Regarding different parts of the oral system, these reactions can be categorized to oral mucosa and tongue, periodontal tissues, dental structures, salivary glands, cleft lip and palate, muscular and neurological disorders, taste disturbances, drug-induced oral infection, and facial edema. In this article, the drugs that may cause adverse effects in the mouth and related structures are reviewed.

The knowledge about drug-induced oral adverse effects helps health professionals to better diagnose oral disease, administer drugs, improve patient compliance during drug therapy, and may influence a more rational use of drugs.

Keywords: Oral reactions, drug reactions, adverse drug effects, side effects, oral mucosal reactions

Citation: Abdollahi M, Radfar M. A Review of Drug-Induced Oral Reactions. J Contemp Dent Pract 2003 February;(4)1:010-031.

(C) Seer Publishing 


\section{Etiology and Pathogenesis of Oral Adverse Drug Reactions ${ }^{1-3}$}

Although the skin is more commonly involved in adverse reactions to drugs, the oral mucosa is also frequently affected. Virtually any drug has the potential to cause an untoward reaction, but some have a greater ability to do so than others. Pathogenesis of drug reactions may be related to either immunologic or nonimmunologic mechanisms. Most adverse reactions to drugs are mediated by the immune system and are drug allergies. Three mechanisms have been proposed for drug allergies. Firstly, IgE-mediated reactions

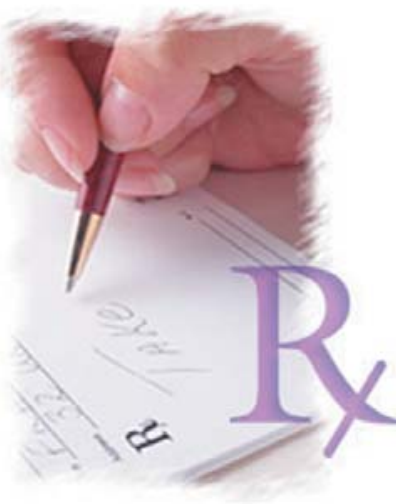
occur when the drug reacts with IgE antibodies bound to mast cells. Secondly, drug allergies can involve a cytotoxic reaction in which an antibody binds to a drug that is already attached to a cell surface. The third mechanism in a drug allergy involves circulation of the antigen for extended periods allowing sensitization of the patient's immune system and production of a new antibody. Nonimmunologic drug reactions are not antibody dependent and may directly affect mast cells causing the release of chemical mediators. Also some nonimmunologic drug-induced reactions result from a drug overdose or toxicity.

\section{Clinical Features of Oral Adverse Drug Reactions ${ }^{1,2}$}

Manifestations of drug reactions are dependent on the type of drug, drug dose, and individual patient differences. These reactions can be seen either rapidly or several days after drug use. Acquired angioedema is an IgE-mediated drug allergy that is commonly observed as drug and food reactions. Other cutaneous manifestations of drug reactions include urticaria, maculopapular rash, erythema, vesicles, ulcers, and target lesions. An unusual form of drug reaction is known as fixed drug reaction during which an erythematous lesion appears in the same location with each antigenic challenge. Oral manifestations of drug reactions may be erythematous, vesicular, or ulcerative in nature. They may also mimic erosive lichen planus known as lichenoid drug reactions.

\section{Histopathology of Oral Adverse Drug Reactions ${ }^{1,2}$}

Histologic features or findings of drug reactions include nonspecific features as spongiosis, apoptotic keratinocytes, lymphoid infiltrates, eosinophils, and ulceration. Also, mononuclear or polymorphonuclear infiltrations in a subepithelial or perivascular distribution, basal cell destruction, edema, and keratinocyte necrosis are seen.

\section{Diagnosis of Adverse Drug Reactions ${ }^{1,2}$}

The diagnosis of drug reactions requires a high index of suspicion and careful history taking. Recent use of a drug is important. Withdrawal of the suspected drug should result in improvement, and reinstitution of the drug should exacerbate the patient's condition. The clinical expression of lesions in drug reactions is generally allergic in nature that can help with the diagnosis.

\section{Effects of Drugs on Oral Mucosa and Tongue ${ }^{1,2,4}$}

Oral mucosal membranes may be the sole site of involvement, or they may be a part of a more generalized skin reaction to the offending drug. The main type of hypersensitivity reaction that affects oral mucosa is a delayed reaction mediated by sensitized T-lymphocyte. Stomatitis medicamentosa, or fixed drug eruption, occurs with systemic drug usage and stomatitis venenata appears with contact hypersensitivity. Lesions associated with fixed drug eruption are erythematous in mild cases and appear ulcerated in severe cases. The reactions usually appear in 24 hours post-ingestion of the drug. Delayed reaction (up to two weeks) has been noted after use of ampicillin. ${ }^{2}$ Withdrawal of the causative drug results in resolution of the lesions. Drugs with the potential to cause fixed drug eruptions are shown in Table 1.

Contact stomatitis is a local reaction of the mucosa after repeated contact with the causative agent. Reactions can be seen as erythematous to ulcerative lesions. The patient may complain of a burning sensation in the mouth together with xerostomia. The reaction may develop from days to years post-exposure to the causative agent. Compounds with potential to cause contact stomatitis are shown in Table 2. 
Table 1. Drugs with potential to cause fixed drug eruptions

\begin{tabular}{|l|l|}
\hline Barbiturates & Lidocaine \\
\hline Chlorhexidine & Penicillamine \\
\hline Gold & Salicylates \\
\hline Indomethacin & Sulphonamides \\
\hline
\end{tabular}

\section{Aphthous Stomatitis ${ }^{5}$}

Aphthous stomatitis (canker sores) is commonly observed and is mediated by the immune system. Lesions usually appear as painful, tiny, discrete, or grouped papules and vesicles. These lesions are small in diameter with round, shallow ulcerations predominantly seen over the labial and buccal mucosa. The reactions heal without scarring in 10-14 days, however, recurrence is common. Drugs with potential to cause aphthous stomatitis are shown in Table 3.

\section{Burning Mouth Syndrome}

This syndrome may occur due to psychogenic factors, hormonal withdrawal, folate, iron, pyridoxine deficiency, or hypersensitivity reactions to the materials utilized in dental prostheses. ${ }^{1}$ There is a case report of burning mouth syndrome after taking clonazepam. ${ }^{6}$ Cases of "scalded mouth" caused by captopril, lisinopril, and enalapril have been described. ${ }^{7-9}$ The mechanism of ACE-inhibitor "scalded mouth" is uncertain, but it may be a subclinical manifestation of lichen planus.

\section{Glossitis $^{5}$}

Glossitis is inflammation of the tongue that is characterized by swelling and intense pain that may be referred to the ear area. Salivation, fever, and enlarged regional lymph nodes may develop during an infectious disease or after a burn, bile, or other injury. Drugs that have potential to cause glossitis are shown in Table 4.

\section{Erythema Multiforme (Stevens-Johnson Syndrome) $)^{1,5,10-12}$}

Erythema muultiforme, which when severe is termed Stevens-Johnson Syndrome, is a mucocutaneous disorder characterized by various clinical types of lesions. Young male adults are predominantly affected. The lips are swollen, crusted, and bleeding. Widespread erythema can be seen within the mouth. The oral lesions disappear within 14 days of drug withdrawal. Only 4\% of erythema multiforme reactions are caused by drugs, however, $80 \%$ of cases occur in StevensJohnson Syndrome. Drugs with potential to cause erythema multiforme are shown in Table 5.

\section{Oral Ulceration $1,{ }^{13-16}$}

A number of chemicals used by dental surgeons can cause "burns" of the oral mucosa, i.e., trichloroacetic acid used in the treatment of pericoronitis. Others that may cause local irritation or ulceration of the mouth include those listed in Table 6.

\section{Vesiculo-bullous Lesions ${ }^{1}$}

The exact mechanism of this reaction is unclear, but it seems to be the consequence of a direct irritant effect. Patients using steroid inhalers for more than 5 years are more prone to the development of oral blistering. This type of reaction has also been reported for naproxen and penicillamine.

\section{Lichenoid Eruptions $s^{1,2}$}

Unlike true lichen planus, drug-induced lichenoid eruptions disappear after drug withdrawal. Lichenoid drug eruptions rarely affect the buccal mucosa. A characteristic white lace pattern may be present. It is thought that drugs causing lichenoid reactions only uncover the latent disease of lichen planus, or amplify a previous disorder, rather than inducing the disease de novo. Such drugs are listed in Table 7.

\section{Color Changes of Oral Mucosa and Teeth}

Discoloration can occur after direct contact with or following systemic absorption of a drug. Historically, exposure to metals like silver, bismuth, gold, lead, mercury, zinc, and copper were the main causative agents of tissue discoloration. Color changes are typically seen along the gingival margins and are caused by the formation of metallic sulphides as a result of reactions with plaque products in gingival pockets. The exact 
Table 2. Compounds with potential to cause contact stomatitis include ${ }^{1,2}$

\begin{tabular}{|l|l|}
\hline Antibiotics & lodine \\
\hline Antiseptic lozenges & Mouthwashes \\
\hline Chewing gum & $\begin{array}{l}\text { Toothpastes (especially those } \\
\text { containing cinnamonaldehyde, } \\
\text { formalin and herbal components) }\end{array}$ \\
\hline Cosmetics & Topical anesthetics \\
\hline $\begin{array}{l}\text { Dental materials (amalgam, } \\
\text { steel wires, beryllium, } \\
\text { palladium, platinium, acrylic } \\
\text { components) }\end{array}$ & Topical steroids \\
\hline Food additives & \\
\hline
\end{tabular}

Table 3. Drugs with potential to cause aphthous stomatitis

\begin{tabular}{|l|l|}
\hline Azathiopurine & Losartan \\
\hline Captopril & NSAIDs \\
\hline Cyclosporine & Olanzapine \\
\hline Fluoxetine & Penicillamine \\
\hline Gold compounds & Sertraline \\
\hline Indinavir & Sulfonamides \\
\hline Interferons & \\
\hline
\end{tabular}

Table 4. Drugs that have potential to cause glossitis

\begin{tabular}{|l|l|l|}
\hline Atrovastatin & Etidronate & Penicillamine \\
\hline Benzodiazepines & Fluoxetine & Penicillins \\
\hline Bleomycin & Fluvoxamine & Rivastigmine \\
\hline Captopril & Gabapentin & Serteraline \\
\hline Carbamazepine & Gold compounds & Sildenafil \\
\hline Cephalosporines & Imipenem/cilastatin & Sulfonamides \\
\hline Chloramphenicol & Lansoprazole & Tacrine \\
\hline Chlorhexidine & Mefenamic acid & Tetracyclines \\
\hline Clarithromycin & Mercaptopurine & Triamterene \\
\hline Clomipramine & Methotrexate & Tricyclic antidepressants \\
\hline Cyclosporine & Metronidazole & Trihexyphenidyl \\
\hline Doxepin & NSAIDs & Venlafaxine \\
\hline Enalapril & Olanzapine & \\
\hline
\end{tabular}


Table 5. Drugs with potential to cause erythema multiforme

\begin{tabular}{|l|l|l|}
\hline Allopurinol & Ginseng & Penicillins \\
\hline Barbiturates & Gold compounds & Phenothiazines \\
\hline Carbamazepine & $\begin{array}{l}\text { lodine-containing } \\
\text { mouth washes }\end{array}$ & Phenytoin \\
\hline Chlorpropamide & Sulphonamides & Rifampicin \\
\hline Clindamycin & Minoxidil & Tetracyclines \\
\hline $\begin{array}{l}\text { Combination of antimalarial } \\
\text { drugs (chloroquine and } \\
\text { sulfadoxine-pyrimethamine) }\end{array}$ & NSAIDs & Tolbutamide \\
\hline Estrogens/Progestins & Penicillamine & Verapamil \\
\hline Ethambutol & & \\
\hline
\end{tabular}

Table 6.

Drugs with potential to cause local irritation of the mouth

\begin{tabular}{|l|l|l|}
\hline Anticancer drugs & Isoproterenol & Potassium chloride tablets \\
\hline Aspirin & Lithium & Tetracyclines \\
\hline Cocaine & NSAIDs & $\begin{array}{l}\text { Toothache solutions (menthol, phenol, clove oil, } \\
\text { camphor and chloroform) }\end{array}$ \\
\hline Ergotamine Tartrate & Pancreatin & \\
\hline Hydrogen peroxide & Paraquat &
\end{tabular}

Drugs with potential to cause oral ulceration 10,17

\begin{tabular}{|l|l|l|}
\hline Alendronate & Enalapril & Naproxen \\
\hline Allopurinol & Erythromycin & Olanzapine \\
\hline Alprazolam & Fluconazole & Penicillamine \\
\hline Aspirin & Fluoxetine & Penicillins \\
\hline Atrovastatin & Ganciclovir & Phenytoin \\
\hline Azathiopurine & Gold compounds & Proguanil \\
\hline Barbiturates & Hydralazine & Promethazine \\
\hline Bleomycin & Hydroxyurea & Propranolol \\
\hline Captopril & Ibuprofen & Propylthiouracil \\
\hline Chlorambucil & Imipramine & Quinidine \\
\hline Chloramphenicol & Indomethacin & Ritonavir \\
\hline Chloroquine & Lamotrigine & Saquinavir \\
\hline Chlorpromazine & Levamisole & Streptomycin \\
\hline Cisplatin & Lithium & Sulfonamides \\
\hline Clofibrate & Melphalan & Terbutaline \\
\hline Clonazepam & Mesalamine & Tetracycline \\
\hline Codeine & Methimazole & Venlafaxine \\
\hline Cyclosporine & Methotrexate & Vincristine \\
\hline Cytarabine & Metronidazole & Warfarin \\
\hline Disopyramide & Mitomycin & Zidovudine \\
\hline Doxorubicin & & \\
\hline
\end{tabular}

5

The Journal of Contemporary Dental Practice, Volume 3, No. 4, November 15, 2002 


\begin{tabular}{|l|l|}
\hline Table 7. Drugs with potential to cause oral lichenoid changes \\
\hline Allopurinol & Mercury (Amalgam) \\
\hline $\begin{array}{l}\text { Angiotensin-converting enzyme } \\
\text { inhibitors }\end{array}$ & Methyldopa \\
\hline Arsenical Compounds & NSAIDs \\
\hline B-blockers & Palladium \\
\hline Bismuth & Penicillamine \\
\hline Chloroquine & Phenothiazines \\
\hline Chlorpropamide & Propranolol \\
\hline Furosemide & Quinidine \\
\hline Gold compounds & Streptomycin \\
\hline Hydroxychloroquine & Tetracyclines \\
\hline Lithium Carbonate & Thiazides \\
\hline Mepacrine & Tolbutamide \\
\hline
\end{tabular}

mechanism of tissue discoloration by many drugs is uncertain but generally resolves within weeks to months when the offending drug is withdrawn, although sometimes it is permanent. For antimalarial drugs like quinolones including chloroquine and mepacrine, the deposit of melanin or iron in mucosal tissues has been suggested. Phenothiazines, especially chlorpromazine, in long-term use produce widespread mucosal pigmentation which is caused by accumulation of a drug metabolite in the tissue. ${ }^{1,2}$ Smokers' melanosis, characterized by increased melanin formation especially in the attached gingiva, has been described, but in view of the prevalence of smoking, is less common or conspicuous than might be expected. ${ }^{10}$

Pigmentation of the oral mucosa can also be caused by the use of oral contraceptives, and cessation of the drug does not produce complete regression of the pigmentation. Estrogens are well known to induce high levels of cortisol binding globulin that contribute to a decreased portion of plasma free cortisol and as a result produces a hypersecretion of ACTH and B-melano-stimulating. The later may cause the increased oral pigmentation. ${ }^{1}$ Minocycline-induced oral pigmentation consequent to interaction of drug with the bone during its formation is most common. Almost all cases of intraoral pigmentation represent minocycline staining of the underlying bones without involvement of the overlying oral mucosa surfaces. ${ }^{18}$
Pigmented lesions of the tongue (dark macular patches) are reported to occur in heroin addicts who inhale the smoke. Histologically the lesions are packed with melanocytes but the mechanism is uncertain. Also, breakdown of methyldopa or its metabolites produce melanin, a product of dopa metabolism; biopsy material was not available to prove this suggestion. There has been no report for other drugs which may increase blood dopa levels. ${ }^{1}$ Drugs and chemicals with potential to cause oral pigmentation are listed in Table 8.

A close correlation exists between plaque removal capability and discoloration after chlorhexidine rinses. Three possible mechanisms for chlorhexidine-induced staining include non-enzymatic browning reactions, formation of pigmented metal sulphides, and dietary factors. Drugs and chemicals with potential to cause tooth discoloration are listed in Table 9. Extrinsic stains are located on the surface of the tooth and are most easily removed by external cleaning. Intrinsic stains are located within the tooth and are accessible only by bleaching. Some extrinsic stains that remain on the tooth for a long time become intrinsic. By recognizing the likely cause of the stain, the dentist can better tell the patient the rate at which the teeth may lighten in color and the limits on the amount of improvement that can be expected after treatment. ${ }^{20}$ Tetracycline can cause the most common distracting, generalized type of intrinsic discoloration. It is hypothesized to occur by the 


\begin{tabular}{|c|c|c|}
\hline Drug/chemical & Color & Site \\
\hline Amalgam & Gray & Gingiva \\
\hline Amalgam & Brown (Tattoo) & Tongue \\
\hline Amodiaquine & Blue-gray/black & Palate \\
\hline Arsenic & Brown & Tongue \\
\hline Aspirin & White & - \\
\hline Bismuth & Blue-gray/Blue-black/Brown & Gum lines/mucosa/tongue \\
\hline Bromine & Brown & Tongue \\
\hline Busulfan & Brown & Mucosa \\
\hline Chlorhexidine & White & Tongue \\
\hline Chloroquine & Blue-grey & Hard Palate, gingiva, lip \\
\hline Coal & Metal dust dark & Mucosa \\
\hline Copper salts & Blue-green & Gum lines \\
\hline Cyclophosphamide & & - \\
\hline Doxorubicin & Dark/Brown & Mucosa/Tongue \\
\hline Gold & Purple & Gingiva \\
\hline Heroin inhalation & Dark macular patch & Tongue \\
\hline Iron & Dark & - \\
\hline Lead & Blue-gray/Blue & Gum Lines/tongue \\
\hline Manganese & Dark & - \\
\hline Mepacrine & Yellow & Mucosa \\
\hline Mercury & Blue-gray/Blue-black & Gum Line/Buccal \\
\hline Methyldopa & Darkening & Tongue \\
\hline Oral contraceptives & Dark & Mucosa \\
\hline Phenolphthalein & Brown & Tongue \\
\hline Phenothiazines & Blue-grey & Mucosa \\
\hline Quinacrine & Gray/Brown & Palate/tongue \\
\hline Quinidine & Blue-Black & Palate \\
\hline Quinine & Brown & - \\
\hline Silver Salts & Gray & Gingiva \\
\hline Thallium & Blue-gray & Gum lines \\
\hline Tin & Dark & - \\
\hline Tobacco & Hazy gray or Brown & - \\
\hline Vanadium & Green & Tongue \\
\hline Zidovudine & Dark & Soft palate, gingival, lips, tongue \\
\hline
\end{tabular}




\begin{tabular}{|l|l|}
\hline \multicolumn{2}{|l|}{ Table 9. Drugs and chemicals with potential to cause tooth discoloration $1,19,22$} \\
\hline Drugs/Chemical & Color \\
\hline Cadmium & Yellow ring \\
\hline Chlorhexidine & Yellow - brown \\
\hline Chlortetracycline & Gray-brown \\
\hline Ciprofloxacin & Green \\
\hline Copper salts & Green \\
\hline $\begin{array}{l}\text { Iron in combination } \\
\text { with tea }\end{array}$ & Brown \\
\hline Isoproterenol & Chalky white \\
\hline Minocycline & Gray-black \\
\hline Other tetracyclines & Brown-yellow \\
\hline Oxytetracycline & Yellow \\
\hline Tetracycline & Yellow \\
\hline Tobacco & Yellow-brown \\
\hline Tooth paste containing \\
Stannous fluoride & Black or green \\
\hline White wine & Black \\
\hline
\end{tabular}

Table 10. Drugs and chemicals with potential to cause black tongue

Amitriptyline

Lansoprazole

Benztropine

Cephalosporines

Methyldopa

Chloramphenicol

Maprotilline

Clarithromycin

Clomipramine

Nortriptyline

Clonazepam

Penicillins

Streptomycin

Sulfonamides

Corticosteroids

Tobacco

Desipramine

Tetracyclines

Fluoxetine

Thiothixene

Griseofulvin

Imipramine

Tranylcypromine

Vegetable dyes

Table 11. Other drugs with potential to cause gingival hyperplasia

Cotrimoxazole

Phenobarbital

Cyclosporine

Erythromycin

Primidone

Ethosuximide

Sertraline

Sodium valproate

Ketoconazole

Topiramate

Lamotrigine

Lithium

Vigabatrin

\section{8}

The Journal of Contemporary Dental Practice, Volume 3, No. 4, November 15, 2002 
joining of the tetracycline molecule with calcium through the chelation process and a subsequent incorporation into the hydroxyapatite crystal of the tooth during the mineralization stage of development. A second theory maintains the discoloration involves a binding of the tetracycline to the tooth structure by a metal organic matrix combination of the tetracycline complex. ${ }^{21}$

\section{Black Hairy Tongue (Lingua villosa nigra) $)^{1,5,10,19}$} In this condition there is an elongation of the filiform papillae of the tongue to form hair-like overgrowth that becomes stained brown or black due to proliferation of chromogenic microorganisms. Black hairy tongue can be seen with the administration of oral antibiotics, poor dental hygiene, and excessive smoking in adults. Drugs and chemicals with potential to cause black tongue include those listed in Table 10.

\section{Postmortem Pink-Red Coloration ${ }^{19}$}

Tooth coloration of this nature is due to hemolysis and exudation of hemoglobin to dental pulp and is enhanced in the presence of moisture and increased venous pressure. Specific conditions of death associated with this phenomenon include drowning, aspiration pneumonitis, and suffocation. Overdoses with barbiturates and carbon monoxide also demonstrate similar findings.

\section{Drug Induced Gingival Hyperplasia ${ }^{1,2,5,10,19,17,23}$} The growth starts as a painless, beadlike enlargement of the interdental papilla and extends to the facial and lingual gingival margin. The enlargement is usually generalized throughout the mouth but is more severe in the maxillary and mandibular anterior regions. Plaque removal and good oral hygiene may benefit in a fast recovery and limits the severity of the lesion but the lesion does not completely resolve. It is hypothesized that in noninflamed gingiva, fibroblasts are less active or even quiescent and do not respond to circulating drugs; fibroblasts within inflamed tissue are in an active state as a result of inflammatory mediators and the endogenous growth factors. It is known that causative drugs inhibit $\mathrm{Ca}^{2+}$ uptake on gingival fibroblasts that correlates with the rate of fibroblast proliferation. Drug variables, plaque-induced inflammatory changes in the gingival tissues, and genetic factors should be considered. The last determines the heterogeneity of the gingival fibro- blast and could also influence drug pharmacokinetics and pharmacodynamics.

Phenytoin, cyclosporine-A, calcium channel blockers, and oral contraceptives are the main causative agents of gingival hyperplasia. Several mechanisms have been suggested for druginduced gingival hyperplasia. Cyclosporine-A has been shown to increase the fibroblast production of collagen and protein, leading to extracellular collagen and matrix formation and to decreased collagenase activity. The increased levels of interlukin- 6 and TGF- $B$ and the decreased levels of gamma-interferon observed during cyclosporine-A therapy may favor the fibroblast synthesis of collagen. ${ }^{24}$ Also, it has been reported the keratinocyte growth factor receptor is up-regulated by cyclosporine- $\mathrm{A}^{25}$, and there is evidence that cyclosporine-A regulates cytokine expression in gingival tissue. $^{26}$

There is evidence that mast cell mediated androgen action in the gingiva in response to phenytoin could contribute to gingival overgrowth. ${ }^{27}$ The incidence of phenytoin-induced gingival overgrowth is approximately 50 percent, but it is higher in both teenagers and institutionalized epileptics. Gingival overgrowth usually becomes apparent during the first 3 months after starting phenytoin and is most rapid in the first year. Unlike phenytoin hyperplasia, cyclosporine-induced hyperplasia is reversible following cessation of drug use. ${ }^{28}$

Nifedipine, the most commonly used calcium channel blocker, induces gingival enlargement in $20 \%$ of the cases. Amlodipine, diltiazem, felodipine, nitrendipine, and verapamil also induce gingival overgrowth. The dihydropyridine derivative isradipidine does not induce gingival overgrowth. Inhibition of apoptosis by nifedipine and resultant epithelial hyperplasia has been reported. ${ }^{29}$ There is also evidence that nifedipine inhibits both adherence- and lipoploysaccharide-stimulated macrophage-induced death of fibroblasts which results in gingival overgrowth. ${ }^{30}$ Nifedipine is frequently prescribed to organ transplant patients to reduce the nephrotoxic effects of cyclosporine and, thus, an additive effect on the gingival tissues is usually observed. ${ }^{31}$

The incidence of gingival overgrowth by oral contraceptives is not rare and resolves when the drug 
is withdrawn. There is evidence the accumulation of metabolic products of the naturally occurring sex hormones in gingiva is an important factor in the pathogenesis of chronic gingivitis. The prevalence and percentage of incidence is uncertain. Maintenance of adequate plaque control is important for gingival health during the administration of oral contraceptives. Other drugs with potential to cause gingival hyperplasia are listed in Table 11.

\section{Salivary Glands $s^{1,5,32-48}$}

The salivary glands are under control of the autonomic nervous system, mainly the parasympathetic division. Salivary gland function can be affected by a variety of drugs that can produce xerostomia or ptyalism. It is suggested this is due to both the reduced salivary flow rate and to a decrease in salivary calcium and phosphate con-

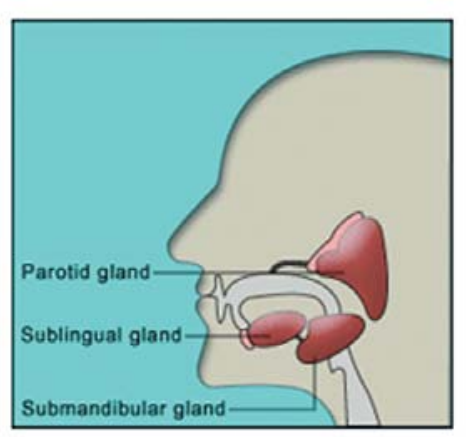

centration caused by such drugs as amphetamines. Submandibular and parotid glands, the major salivary glands of the body, have important roles in maintaining the health of the oral cavity and gastrointestinal tract. Altered salivary flow rate and levels of secretory proteins or enzymes may cause destructive effects on oral and dental health and wound healing rates directly through lower levels of specific growth factors being present. It is known that salivary mucins and growth factors are involved in the maintenance of mucosal integrity due to their ability to trap water, thereby, preventing injury through desiccation; growth factors may assist in tissue regeneration. The epidermal growth factor that is secreted from salivary glands has a potential role in oral wound healing. ${ }^{49}$ Common oral manifestations resulting from decreased salivary flow include increased dental caries, fungal infections, bacterial infec- tions, aphthous lesions, and dysphagia. Systemic drug therapy can also produce pain and swelling of the salivary glands. ${ }^{50}$ Table 13 lists drugs and chemicals with potential to inhibit the function of salivary glands.

Sjogren's Syndrome includes parotid swelling. However, parotid enlargement in Sjogren's Syndrome occurs relatively late in the course of rheumatoid arthritis. Its sudden appearance in the early stages of the disease may well indicate an adverse reaction to an anti-inflammatory drug since the $\mathrm{H}^{2}$-receptor antagonists have been reported to aggravate the disease. The swelling is quite common in rheumatoid arthritis, for which NSAIDs are frequently used, therefore, salivary gland swelling could be part of the disease rather than a complication of its treatment. Sjogren's Syndrome is often (30\%) seen in association with other autoimmune rheumatic diseases. ${ }^{55}$

\section{Effects on Dental Structure ${ }^{1,32-34,56-58}$}

Systemic drug therapies can also affect the oral environment, most notably when causing xerostomia. Xerostomia is the reduction of salivary flow as well as a change in the quality of the saliva, both of which increase the risk of dental caries. A large number of drugs including tricyclic antidepressants, benzodiazepines, lithium, and morphine may cause xerostomia. Some of the common problems associated with dry mouth include a constant sore throat, burning sensation, problems in speaking, difficulties in swelling, hoarseness or dry nasal passage. Left untreated, dry mouth can damage teeth structure. Without adequate saliva to lubricate mouth, wash away food, and neutralize the acids produced by plaque, extensive decay can occur. Dryness of mouth and severely dry lips are also the side effects of isotretinoin therapy for acne. Table 12 lists other agents with the potential to affect dental structures from reduced saliva flow rate.

\begin{tabular}{|l|l|}
\hline Table 12. Other agents with potential to affect dental structures & $1,10,39,54$ \\
\hline Antineoplastic agents & Maternal smoking \\
\hline B-Blockers & Phenytoin \\
\hline Cocaine & Radiotherapy \\
\hline Doxapram & $\begin{array}{l}\text { Sympathomimetics or corticosteroids } \\
\text { as inhaled powders or aerosols }\end{array}$ \\
\hline Local anesthetics & \\
\hline
\end{tabular}




\begin{tabular}{|c|c|}
\hline Benzodiazepines & Morphine \\
\hline Cadmium & Nifedipine \\
\hline Cyclosporine & Nitric oxide inhibitors \\
\hline Diltiazem & Ofloxacin \\
\hline Gentamicin & Rubidium \\
\hline Lead & Verapamil \\
\hline \multicolumn{2}{|l|}{ Lithium } \\
\hline \multicolumn{2}{|c|}{ Drugs that can cause dryness of mouth } \\
\hline Amphetamine & Omeprazole \\
\hline Anticholinergics & Ondansetron \\
\hline Antihistamines & Selective serotonin reuptake inhibitors \\
\hline Antineoplastic drugs & Thiabendazole \\
\hline Anti-HIV protease inhibitors & Tramadol \\
\hline Didanosine & Tricyclic antidepressants \\
\hline \multicolumn{2}{|l|}{ Levodopa } \\
\hline \multicolumn{2}{|c|}{ Drugs that can cause sialorrhea } \\
\hline Alprazolam & Levodopa \\
\hline Amiodarone & Lithium \\
\hline Bethanechol & Mefenamic Acid \\
\hline Buspirone & Mercurial salts \\
\hline Clozapine & Niridazole \\
\hline Diazoxide & Pentoxifylline \\
\hline Edrophonium & Pilocarpine \\
\hline Gentamycin & Risperidone \\
\hline Guanethidine & Rivastigmine \\
\hline Imipenem/Cilastatin & Succinylcholine \\
\hline lodides & Tacrine \\
\hline Kanamycin & Tobramycin \\
\hline Ketamine & Venlafaxine \\
\hline Lamotrigine & Zaleplon \\
\hline \multicolumn{2}{|c|}{ Drugs that have potential to cause swelling and/or pain in salivary } \\
\hline Bretylium & Naproxen \\
\hline Catecholamine inhalation & Nifedipine \\
\hline Chlorhexidine & Nitrofurantoin \\
\hline Cimetidine & Phenytoin \\
\hline Clonidine & Ranitidine \\
\hline Deoxycycline & Ritodrine \\
\hline Famotidine & Sulfonamides \\
\hline lodine & Trimipramine \\
\hline Methyldopa & Warfarin \\
\hline
\end{tabular}

\section{1}

The Journal of Contemporary Dental Practice, Volume 3, No. 4, November 15, 2002 


\begin{tabular}{|c|c|}
\hline Acetazolamide & Nicotinic acid \\
\hline Amitriptyline & Nitrofurantoin \\
\hline Chlorpropamide & Pentamidine \\
\hline Ergotamine & Polymyxin B \\
\hline $\begin{array}{l}\text { Gonadotropin-releasing-hormone } \\
\text { analogues }\end{array}$ & Propranolol \\
\hline Hydralazine & Streptomycin \\
\hline Isoniazid & Tolbutamide \\
\hline Nalidixic acid & \\
\hline
\end{tabular}

\section{Muscular and Neurological Disorders \\ Tardive dyskinesia that affects the elderly, particu- larly women, taking antipsychotic drugs for many years, is an uncommon and sometimes unrecog- nized cause of orofacial pain. Tardive dyskinesia is a painless syndrome in itself, but secondary orofacial pain can result from chronic mild trauma between a denture-bearing mucosa and dentures with abnormal movement.}

Facial pain has also been reported following the use of a controlled-release theophylline preparation. Table 14 lists drugs reported to cause sensation of numbness, tingling, or burning in the face or mouth.

\section{Taste Disturbance ${ }^{1,48}$}

Many drugs induce abnormalities of taste by processes not yet fully understood. The alteration in taste may be simply a blunting or decreased sensitivity in taste perception (hypogeusia), a total loss of the ability to taste (ageusia), or a distortion in perception of the correct taste of a substance, for example, sour for sweet (dysgeusia). A widerange of drugs give rise to dysgeusia or hypogeusia either by interfering in chemical composition or flow of saliva, or, more specifically, affecting taste receptor function or signal transduction. Sulfhydryl compounds are a common cause of taste disturbance. Drugs with the potential for affecting taste are listed in Table 15.

\section{Taste Disturbance ${ }^{1,48}$}

In many patients, penicillamine causes partial or total loss of taste. It seems there is a marked difference in the frequency of this effect between patients being treated for Wilson's disease and those being treated for other conditions. In patients treated for Wilson's disease, frequency is much lower. Loss of taste has been found to be dose related. It appears that taste disturbance is reversible within a period of 8-10 weeks, whether or not penicillamine is discontinued. ${ }^{5}$

Am impaired salty taste is a frequent complaint associated with Captopril. The extent of Captoprilinduced dysgeusia seems to be related to dose and renal function and can be compounded by smoking. Taste disturbances tend to be self-limiting and reversible in 2-3 months even if the drug is continued. ACE inhibitors can also cause a persistent chronic dry cough.

Systemic griseofulvin can render certain foods profoundly tasteless, the effect gradually worsening for as long as the patient takes the drug. Furthermore, the effect may take some months to disappear after the drug is withdrawn. In addition, other drugs especially those used for gastrointestinal disorders may cause some degree of loss of taste or altered taste as follows: tripotassium dicitrato bismuthate chelate, Clarithromycin, lansoperazole, anti-HIV protease inhibitors, terbinafine, intravenous pentamidine, and isotretinoin. ${ }^{48}$

\section{Halitosis \\ Halitosis is the offensive breath resulting from poor oral hygiene, dental or oral infections, inges- tion of certain foods, use of tobacco, and some systemic diseases. Disulfiram and sublingual iso- sorbide dinitrate can cause halitosis. Drugs caus- ing xerostomia, discussed earlier, may indirectly cause or aggravate this problem.}




\begin{tabular}{|c|c|c|}
\hline Acarbose & Dicyclomine & Pentamidine \\
\hline Acetazolamide & Enalapril & Phenytoin \\
\hline Amitriptyline & Etidronate & Propantheline \\
\hline Aspirin & Fluoxetine & Propylthiouracil \\
\hline Atrovastatin & Fluvoxamine & Rifabutin \\
\hline Captopril & Indomethacin & Ritonavir \\
\hline Ceftirizine & Isotretinoin & Rivastigmine \\
\hline Cisplatin & Levodopa & Spironolactone \\
\hline Clidinium & Losartan & Sulfadoxine \\
\hline Clomipramine & Methimazole & Topiramate \\
\hline Cocaine & Penicillamine & Venlafaxine \\
\hline \multicolumn{3}{|l|}{ Diazoxide } \\
\hline \multicolumn{3}{|c|}{ Drugs with potential to cause dysgeusia ${ }^{1,5}$} \\
\hline Acetaminophen & Dipyridamole & Minoxidil \\
\hline Acetazolamide & Donepezil & Naratriptan \\
\hline Acyclovir & Dorzolamide & Nifedipine \\
\hline Albuterol & Doxepin & Nortriptyline \\
\hline Alendronate & Deoxycycline & Ofloxacin \\
\hline Allopurinol & Enalapril & Olanzapine \\
\hline Alprazolam & Etidronate & Omeprazole \\
\hline Amiloride & Famotidine & Pamidronate \\
\hline Amiodarone & Fenfluramine & Penicillamine \\
\hline Amitriptyline & Fentanyl & Penicillins \\
\hline Amlodipine & Flecainide & Pentazocine \\
\hline Amoxicillin & Fluconazole & Pentoxifylline \\
\hline Aspirin & Fluorouracil & Pergolide \\
\hline Atrovastatin & Fluoxetine & Perindopril \\
\hline Atropine sulfate & Flurazepam & Phytonadione \\
\hline Baclofen & Fluvastatin & Pilocarpine \\
\hline Benztropine & Fluvoxamine & Potassium iodide \\
\hline Bromocriptine & Gancyclovir & Procainamide \\
\hline Buspirone & Gemfibrozil & Propantheline \\
\hline Busulfan & Glyburide & Propranolol \\
\hline Calcitonin & Gold compounds & Propylthiouracil \\
\hline Captopril & Granisetron & Pyrimethamine \\
\hline Carbamazepine & Griseofulvin & Quinidine \\
\hline Cephalosporines & Hydrochlorothiazide & Ranitidine \\
\hline Celecoxib & Hydroxychloroquine & Ribavirin \\
\hline
\end{tabular}

\section{3}

The Journal of Contemporary Dental Practice, Volume 3, No. 4, November 15, 2002 
Table 15 (continued)

\begin{tabular}{|c|c|c|}
\hline Chlorhexidine & Imipenem/Cilastatin & Riluzole \\
\hline Chlorothiazide & Imipramine & Risperidone \\
\hline Cholestyramine & Indinavir & Ritonavir \\
\hline Ciprofloxacin & Interferons & Rivastigmine \\
\hline Citalopram & Isotretinoin & Saccharin \\
\hline Clarithromycin & Ketoprofen & Selegiline \\
\hline Clidinium & Ketorolac & Serteraline \\
\hline Clindamycin & Labetalol & Simvastatin \\
\hline Clofazimine & Lamotrigine & Sulfonamides \\
\hline Clofibrate & Lansoprazole & Sumatriptan \\
\hline Clomipramine & Leuprolide & Tacrine \\
\hline Clonazepam & Levodopa & Tamoxifen \\
\hline Clonidine & Lisinopril & Terbutaline \\
\hline Clozapine & Lithium & Timolol \\
\hline Codeine & Loratadine & Tocainde \\
\hline Cotrimoxazole & Losartan & Tolazamide \\
\hline Cromolyn & Lovastatin & Tolbutamide \\
\hline Cyproheptadine & Maprotilline & Tolmetin \\
\hline Dacarbazine & Mesalamine & Topiramate \\
\hline Dantrolene & Mesna & Tramadol \\
\hline Desipramine & Metformin & Triamteren \\
\hline Dexfenfluramine & Methamphetamine & Trimipramine \\
\hline Dextroamphetamine & Methimazole & Ursodiol \\
\hline Diazoxide & Methocarbamol & Vancomycin \\
\hline Diclofenac & Methotrexate & Venlafaxine \\
\hline Dicyclomine & Metoprolol & Vinblastine \\
\hline Dihydroergotamine & Metronidazole & Vincristine \\
\hline Diltiazem & Midazolam & Zidovudine \\
\hline
\end{tabular}

The Journal of Contemporary Dental Practice, Volume 3, No. 4, November 15, 2002 


\begin{tabular}{|l|l|}
\hline Table 16. Drugs with potential to cause oral candidiasis & \multicolumn{5}{|l|}{} \\
\hline Cephalosporins & Olanzapine \\
\hline Ciprofloxacin & Omeprazole \\
\hline Claithromycinr & Penicillins \\
\hline Griseofulvin & Riluzole \\
\hline Mesalamine & Tacrolimus \\
\hline
\end{tabular}

\section{Oral Infections Induced or Aggravated by Drugs ${ }^{1}$}

Many types of systemic drug therapy can alter oral flora and, therefore, predispose the mouth to bacterial or fungal infection. Drugs that have been implicated in this problem include corticosteroids, antimicrobials, anticancer drugs, immunosuppressive agents, and oral contraceptives. Drugs causing xerostomia may also potentiate the initiation of oral infections. Table 16 lists drugs with potential to cause oral candidiasis.

\section{Alveolar Osteitis (Dry Socket), ${ }^{1,60}$}

The use of contraceptives has been associated with a significant increase in the frequency of dry sockets (alveolar osteitis) after removal of impacted lower third molars. The probability of dry sockets increases with the estrogen dose in the oral contraceptive. The dry sockets can be minimized by carrying out the extractions during days $23-28$ of the tablet cycle.

\section{Facial Edema/Angioedema ${ }^{1,5}$}

Facial edema is often a manifestation of druginduced hypersensitivity reactions, and angiotensin converting enzyme inhibitors (ACEIs) are the most common cause. It seems that angioedema arises as a consequence of an alternation in bradykinin metabolism in susceptible patients. The most common ACEls implicated in this reaction are captopril, lisinopril, and enalapril. Angioedema usually occurs within hours or at most weeks after starting the ACEl and reverses within hours of stopping. However, it can develop after longterm therapy. Table 17 lists drugs that can cause facial edema.

\section{Stomatodynia}

Stomatodynia is pain in the mouth and can be a consequence of drug reactions. Table 18 lists drugs with the potential to cause this condition.

\section{Cheilitis 5,54}

Cheilitis is an abnormal condition of the lips characterized by inflammation and cracking of the skin.
This is almost always associated with fungal infections and frequently occurs with xerostomia that is drug-induced. Table 19 lists drugs with potential to cause cheilitis.

\section{Conclusion ${ }^{54,61-64}$}

Since most drug reactions occur within 1 to 2 weeks following initiation of therapy, reactions seen after 2 weeks are less likely to be due to medication use. Some reactions are dependent on dosage or cumulative toxicity. The majority of drug-induced oral reactions are moderate in severity. However, severe reactions necessitate rapid withdrawal of the suspected drug. In most cases, the oral reaction will be resolved by symptomatic treatment. Readministration of the offending drug helps to establish whether the oral eruption is drug-induced. Reactions after rechallenge may be

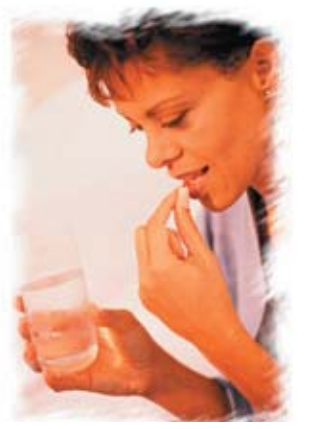
more severe and, therefore, rechallenge should not be performed without medical supervision. Many clients take multiple medications; therefore, dentists must be aware of the issues related to drug use including indications, interactions, and adverse drug effects. The ability to evaluate these issues is necessary to accurately assess client status and prevent situations that compromise client safety. Oral side effects interfere with client function and increase risks for infection, pain, and possible tooth loss. It has been reported the most frequent side-effects of drugs are xerostomia, dysgeusia, and stomatitis.

As a final note, rapid progress in pharmacotherapeutics requires clinicians to constantly update their knowledge of drugs used by their patients. Attention must be paid to their toxic and unwanted effects that in many cases may be similar to characteristics of common diseases. 


\begin{tabular}{|l|l|}
\hline \multicolumn{2}{|l|}{ Table 17. Drugs that can cause facial edema } \\
\hline Adrenomimetic bronchodilators & Intravenous clindamycin \\
\hline Captopril & Lisinopril \\
\hline Droperidol & Mianserin \\
\hline Enalapril & \\
\hline
\end{tabular}

\begin{tabular}{|l|l|}
\hline Table 18. Drugs with potential to cause stomatodynia \\
\hline Benztropine & Potassium lodide \\
\hline Biperidin & Ticarcillin \\
\hline Griseofulvin & Triamteren \\
\hline Lithium & Vitamin A \\
\hline Penicillins & \\
\hline
\end{tabular}

\begin{tabular}{|l|l|}
\hline \multicolumn{2}{|l|}{ Table 19. Drugs with potential to cause cheilitis include } \\
\hline Atrovastatin & Psoralens \\
\hline Busulfan & Ritonavir \\
\hline Clofazimine & Saquinavir \\
\hline Clomipramine & Simvastatin \\
\hline Cyanocobalamin & Streptomycin \\
\hline Gold compounds & Sulfasalazine \\
\hline Indinavir & Tetracycline \\
\hline Isotretinoin & Vitamin A \\
\hline Methyldopa & \\
\hline
\end{tabular}


References

1. Seymour RA. Oral and dental disorders. In: Davies DM, Ferner RE, DeGlanville H. eds., Davies's textbook of adverse drug reactions, 5th ed., London, Chapman \& Hall Medical, 1998: 234-250.

2. Regezi JA, Sciubba JJ. Oral pathology clinical pathologic corrections. 3rd ed., London, W.B. Saunders Company, 1999: 62-65, 158-159, 179, 181, 496.

3. Jacobsen PL. Adverse drug reactions. In: Silverman S, Eversole LR, Truelove EL. Eds., Essentials of oral medicine, London, BC Decker Inc, 2001: 107-110.

4. Moghadam BK, Drisko CL, Gier RE. Chlorhexidine mouthwash-induced fixed drug eruption; case report and review of the literature. Oral Surg Oral Med Oral Pathol. 1991 Apr;71(4):431-4. Review.

5. Litt JZ. Drug eruption reference manual. London, The Parthenon Publishing Group, 2001: 274-421.

6. Culhane NS, Hodle AD. Burning mouth syndrome after taking clonazepam. Ann Pharmacother. 2001 Jul-Aug;35(7-8):874-6.

7. Vlasses $\mathrm{PH}$, Rotmensch $\mathrm{HH}$, Ferguson RK, et. al. Scalded mouth caused by angiotensin converting enzyme inhibitors. Br Med J (Clin Res Ed). 1982 Jun 5;284(6330):1672-3. No abstract available.

8. Savino L, Haushalter HM. Lisinopril-induced scalded mouth syndrome. Ann Pharmacother. 1992 Nov;26(11):1381-2.

9. Brown RS, Krakow AM, Douglas T. Scalded mouth syndrome caused by angiotensin converting enzyme inhibitors: two case reports. Oral Surg Oral Med Oral Pathol Oral Radiol Endod. 1997 Jun;83(6):665-7.

10. Cawson RA, Binnie WH, Barrett AW, et. al. Oral disease, clinical and pathological correlations. 3rd ed., London, Mosby, 2001: 4.13, 11.15, 12.13, 12.14, 13.18, 13.19, 13.33.

11. Dega H, Laporte JL, Frances $\mathrm{C}$, et. al. Ginseng as a cause for Stevens-Johnson syndrome? Lancet. 1996 May 11;347(9011):1344. No abstract available.

12. Lin AY, Baker BA. Verapamil-associated Stevens-Johnson syndrome. DICP. 1989 Dec;23(12):987-8.

13. McAvoy BR. Letter: Mouth ulceration and slow-release potassium tablets. Br Med J. 1974 Oct 19;4(5937):164-5. No abstract available.

14. Nordt SP. Tetracycline-induced oral mucosal ulcerations. Ann Pharmacother. 1996 May;30(5):547-8. No abstract available.

15. Drysdale SF, Phillips-Howard PA, Behrens RH. Proguanil, chloroquine, and mouth ulcers. Lancet. 1990 Jan 20;335(8682):164. No abstract available.

16. Wittkowsky AK, Reddy R, Bardy GH. Oral mucosal ulceration from disopyramide. Ann Pharmacother. 1995 Dec;29(12):1299-1300. No abstract available.

17. Newman MG, Takei HH, Carranza FA. Carranza's clinical periodontology. London, W.B. Saunders Company, 2002:281-285.

18. Eisen D. Disorders of pigmentation in the oral cavity. Clin Dermatol. 2000 Sep-Oct;18(5):579-87. Review. No abstract available.

19. Micromedex Healthcare Series, Drugdex, Drug Consults, Vol. 114, Disk B, 2002.

20. Summitt JB, Robbins JW, Schwartz RS, et. al. Fundamentals of operative dentistry. 2nd ed., Chicago, Quintessence Publishing Co., 2001:402.

21. Aschheim KW, Dale BG. Esthetic dentistry, a clinical approach to techniques and materials. 2nd ed., Philadelphia, Mosby, 2001:247-249.

22. McKenna BE, Lamey PJ, Kennedy JG, et. al. Minocycline-induced staining of the adult permanent dentition: a review of the literature and report of a case. Dent Update. 1999 May;26(4):160-2. Review.

23. Lindhe J, Karring T, Lang NP. Clinical periodontology and implant dentistry. 3rd ed., Copenhagen, Munksgoard, 1997: 346-349.

24. Schincaglia GP, Forniti F, Cavallini R, et. al. Cyclosporin-A increases type I procollagen production and mRNA level in human gingival fibroblasts in vitro. J Oral Pathol Med. 1992 Apr;21(4):181-5.

25. Das SJ, Newman HN, Olsen I. Keratinocyte growth factor receptor is up-regulated in cyclosporine-A induced gingival hyperplasia. J Dent Res. 2002 Oct;81(10):683-7.

26. Myrillas TT, Linden GJ, Marley JJ, et. al. Cyclosporin A regulates interleukin-1beta and interleukin-6 expression in gingiva: implications for gingival overgrowth. J Periodontol. 1999 Mar;70(3):294-300.

27. Soory M, Suchak A. The effects of human mast-cell products and of phenytoin on androgen 5alphareductase expression in human gingival fibroblasts. Arch Oral Biol. 2001 Sep;46(9):847-55. 
28. Hassell TM, Burtner AP, McNeal D, et. al. Oral problems and genetic aspects of individuals with epilepsy. Periodontol 2000. 1994 Oct;6:68-78. Review. No abstract available.

29. Shimizu $Y$, Kataoka $M$, Seto $\mathrm{H}$, et. al. Nifedipine induces gingival epithelial hyperplasia in rats through inhibition of apoptosis. J Periodontol. 2002 Aug;73(8):861-7.

30. Fujimori Y, Maeda S, Saeki M, et. al. Inhibition by nifedipine of adherence- and activated macrophageinduced death of human gingival fibroblasts. Eur J Pharmacol. 2001 Mar 9;415(1):95-103.

31. King GN, Fullinfaw R, Higgins TJ, et. al. Gingival hyperplasia in renal allograft recipients receiving cyclosporin-A and calcium antagonists. J Clin Periodontol. 1993 Apr;20(4):286-93.

32. Dehpour AR, Abdollahi M, Alghasi H. Effects of lithium on rat parotid and submandibulary gland functions. Gen Pharmacol. 1995 Jul;26(4):851-4.

33. Abdollahi M, Safarhamidi H. Protection by nitric oxide of morphine-induced inhibition of rat submandibular gland function. Pharmacol Res. 2002 Feb;45(2):87-92.

34. Abdollahi M., Rahbar-Haghighat M, Soltaninejad K. Prevention by flumazenil of benzodiazepines-suppressed rat submandibular gland function. Indian Journal of Pharmacology 2002;34:164-171.

35. Abdollahi M, Isazadeh Z. Inhibition of rat parotid and submandibular gland functions by ofloxacin, a fluoroquinolone antibiotic. Fundam Clin Pharmacol. 2001 Oct;15(5):307-11.

36. Abdollahi M, Rahmat-Jirdeh N, Soltaninejad K. Protection by selenium of lead-acetate-induced alterations on rat submandibular gland function. Hum Exp Toxicol. 2001 Jan;20(1):28-33.

37. Abdollahi M, Dehpour A, Shafayee F. L-arginine/nitric oxide pathway and interaction with lead acetate on rat submandibular gland function. Pharmacol Toxicol. 2000 Nov;87(5):198-203.

38. Abdollahi M, Dehpour A, Kazemian P. Alteration by cadmium of rat submandibular gland secretory function and the role of the L-arginine/nitric oxide pathway. Pharmacol Res. 2000 Dec;42(6):591-7.

39. Abdollahi M, Dehpour AR, Fooladgar M. Alteration of rat submandibulary gland secretion of protein, calcium and N-acetyl-beta-D-glucosaminidase activity by lead. Gen Pharmacol. 1997 Oct;29(4):675-80.

40. Dehpour AR, Shirzad N, Ghafourifar P, et. al. Effects of cyclosporine A on the functions of submandibular and parotid glands of rats. Gen Pharmacol. 1996 Jul;27(5):887-90.

41. Dehpour AR, Ghafourifar P, Massoudi S, et. al. On the relation of calcium channel blockers to rat parotid and submandibular glands function in vivo. Gen Pharmacol. 1995 May;26(3):619-22.

42. Dehpour AR, Ghafourifar P, Madani F, et. al. Effects of vinca alkaloids on rat parotid and submandibular glands function in vivo. Gen Pharmacol. 1995 Mar;26(2):321-5.

43. Dehpour AR, Abdollahi M. Effects of gentamicin on rat submandibulary gland functions. Gen Pharmacol. 1994 Dec;25(8):1719-22.

44. Ghazi M, Dehpour AR, Abdollahi M, et. al. Lead intoxication in rats and its concentrations in blood and saliva. Toxic Subs Mech 1997;16: 327-385.

45. Abdollahi M, Dehpour AR, Baharnouri G. Alteration by rubidium of rat submandibular secretion of protein and N-acetyl-?-D-glucosaminidase. Toxic Subs Mech 1998;17:121-131.

46. Abdollahi M, Sharifzadeh $\mathrm{M}$, Marzban $\mathrm{H}$, et. al. Alteration by lead acetate of rats submandibular gland morphology and ultrastructure. Toxic Subs Mech 1999;18:139-148.

47. Loria RC, Wedner HJ. Facial swelling secondary to inhaled bronchodilator abuse: catecholamineinduced sialadenosis. Ann Allergy. 1989 Apr;62(4):289-93.

48. Porter SR, Scully C. Adverse drug reactions in the mouth. Clin Dermatol. 2000 Sep-Oct;18(5):525-32. Review. No abstract available.

49. Herrera JL, Lyons MF 2nd, Johnson LF. Saliva: its role in health and disease. J Clin Gastroenterol. 1988 Oct;10(5):569-78. Review.

50. Mandel ID. A contemporary view of salivary research. Crit Rev Oral Biol Med. 1993;4(3-4):599-604.

51. Knulst AC, Stengs CJ, Baart de la Faille H, et. al. Salivary gland swelling following naproxen therapy. Br J Dermatol. 1995 Oct;133(4):647-9.

52. Anibarro B, Fontela JL. Sulfadiazine-induced sialadenitis. Ann Pharmacother. 1997 Jan;31(1):59-60.

53. Ponte CD. A suspected case of trimipramine-induced salivary adenitis. Drug Intell Clin Pharm. 1982 Mar;16(3):248-9. No abstract available.

54. Spolarich AE. Managing the side effects of medications. J Dent Hyg. 2000 Winter;74(1):57-69; quiz 71-2. Review. 
55. Braunwald E, Fauci AS, Kasper DL, et. al. Harrison's principles of internal medicine. 15th ed., New York, McGraw-Hill, 2001:1974.

56. White ID, Hoskin PJ, Hanks GW, et. al. Morphine and dryness of the mouth. BMJ. 1989 May 6;298(6682):1222-3. No abstract available.

57. Hogan DJ, Strand LM, Lane PR. Isotretinoin therapy for acne: a population-based study. CMAJ. 1988 Jan 1;138(1):47-50.

58. American Dental Association, 1995-2002.

59. Jaffe IA. Adverse effects profile of sulfhydryl compounds in man. Am J Med. 1986 Mar;80(3):471-6. Review.

60. Catellani JE, Harvey S, Erickson SH, et. al. Effect of oral contraceptive cycle on dry socket (localized alveolar osteitis). J Am Dent Assoc. 1980 Nov;101(5):777-80.

61. Grisius MM. Salivary gland dysfunction: a review of systemic therapies. Oral Surg Oral Med Oral Pathol Oral Radiol Endod. 2001 Aug;92(2):156-62. Review.

62. Daniels TE, Wu AJ. Xerostomia-clinical evaluation and treatment in general practice. J Calif Dent Assoc 2000;28(12):933-941.

63. Smith RG, Burtner AP. Oral side-effects of the most frequently prescribed drugs. Spec Care Dentist. 1994 May-Jun;14(3):96-102. Review.

64. Moore PA, Gage TW, Hersh EV, et. al. Adverse drug interactions in dental practice. Professional and educational implications. J Am Dent Assoc. 1999 Jan;130(1):47-54.

\section{About the Authors}

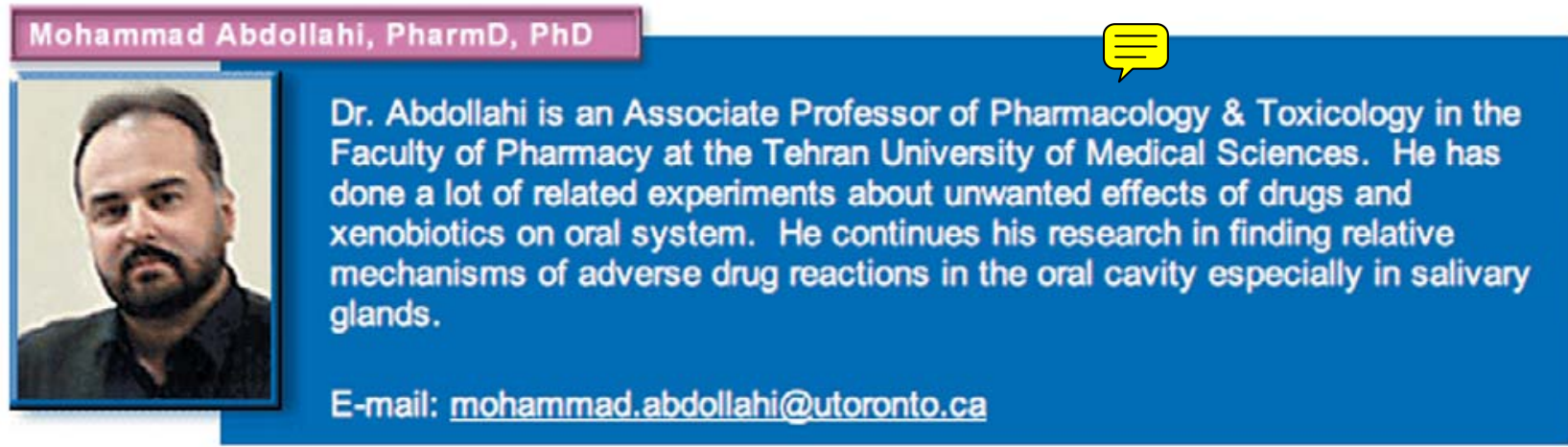

\section{Mania Radfar, PharmD}

Dr. Radfar is a Clinical Pharmacy Resident in the Faculty of Pharmacy at the Tehran University of Medical Sciences. She cooperates with Dr Abdollahi in performing drug-related studies. 